\title{
Effect of Sub-Zero Treatment on the Wear Resistance of P/M Tool Steels
}

\author{
Sobotova $\mathbf{J}^{*}$, Kuřík M, Krum S and Lacza J
}

Faculty of Mechanical Engineering, Czech Technical University in Prague, Karlovo nám 13, 12135 Prague 2, Czech Republic

\begin{abstract}
Sub-zero treatment of tool steels is included within the cycle of conventional heat treatment. This kind of heat treatment has been reported to improve wear resistance of tools. The improvement is attributed to precipitation of fine carbide particles, but is depending on a number of the other factors as well. This paper follows the previous works, in which the effect of sub-zero treatment on the mechanical and structural properties of P/M tool steels was evaluated. Two types of P/M cold work tool steels were used in the research: Vanadis 6 and high speed steel Vanadis 30 . They were austenitized, nitrogen gas quenched and tempered. The 4 hours long sub-zero period of dwell at $-196^{\circ} \mathrm{C}$ was also incorporated between quenching and tempering. Wear evaluation was carried out using a pin-on-disk method. The observed values of wear resistance have been collated with the values of hardness and the bending strength. The results of the work are supplemented by a detailed analysis of the carbide particles of both monitored conditions.
\end{abstract}

Keywords: Sub-zero treatment; Deep cryogenic treatment; P/M tool steel; Wear resistance; SEM; EDS

Abbreviations: CHT: Conventional Heat Treatment; DCT: Deep Cryogenic Treatment; C/M: Conventional Metallurgy; P/M: Power Metallurgy; HSS: High Speed Steel; SEM: Scanning Electron Microscopy; EDS: Energy Dispersive Spectroscopy; HRC: Hardness by Rockwell

\section{Introduction}

Sub-zero treatment (also referred to as cryogenic treatment) is a way of treatment at low temperatures (lower than $-80^{\circ} \mathrm{C}$ ) added to the Conventional Heat Treatment (CHT). Therefore, essentially it is the extension of standard heat treatment processes. In case of tool steels, cryogenic treatment at temperatures ranging from $-140^{\circ} \mathrm{C}$ to $-196^{\circ} \mathrm{C}$, referred to as Deep Cryogenic Treatment (DCT), included between the quenching and tempering is the most commonly used.

The influence of CHT on changes of structural and material characteristics of tool steels is well known [1,2]. The fact that the presence of high alloying elements content decreases the temperature of martensitic transformation start and finish, thereby increasing the fraction of retained austenite in the structure after hardening, is also known. To reduce this undesirable amount of the retained austenite, the cryogenic treatment can be used. Additionally, the authors of summary articles [1-4] and our own work [5,6] published in 2005-2015 addressing this issue agree on a finding that cryogenic processing of tool steels causes precipitation of very fine carbides in the structure. Superposition of both effects leads to a change of properties such as hardness, toughness, wear resistance and dimensional stability.

Based on the known results it can be stated that the effect of the cryogenic treatment on the functional properties of tool steels depends on a number of factors including the chemical composition of the processed material, method of its primary production and its application, the parameters of the cryogenic processing, but the experimental methods of functional properties evaluation as well. From a materials perspective it is logical that the effects of these various factors are mutually intertwined. Also, it is not possible to assume the same degree of sensitivity to these factors for different materials. Generally, it can be said that in the available literature it is possible to clearly find more publications dedicated to monitoring the effect of cryogenic treatment on the functional characteristics of tool steels produced by conventional metallurgy $(\mathrm{C} / \mathrm{M})$ when compared with publications addressing the same issue for the steels produced by powder metallurgy $(\mathrm{P} / \mathrm{M})$. It is known that in case of $\mathrm{P} / \mathrm{M}$ tool steels, finer and more homogeneous structure is achieved in comparison with the $\mathrm{C} / \mathrm{M}$ steels. That is inter alia reflected in higher toughness of the $\mathrm{P} / \mathrm{M}$ steels and their wear resistance at higher cutting speeds.

The aim of the paper is to analyze influence of the DCT on precipitation effect of two tool steels of different chemical composition in connection to wear resistance evaluated in laboratory conditions.

\section{Experimental Procedure}

The experimental material was the $\mathrm{P} / \mathrm{M}$ steel Vanadis 6 nominally containing (in wt.\%) $2.1 \%$ C, $1.0 \% \mathrm{Si}, 0.4 \% \mathrm{Mn}, 6.8 \% \mathrm{Cr}, 1.5 \% \mathrm{Mo}$ and $5.4 \% \mathrm{~V}$ and $\mathrm{P} / \mathrm{M}$ high-speed steel Vanadis 30 containing $1.28 \% \mathrm{C}, 4.2 \%$ Cr, 5.0\% Mo, $6.4 \% \mathrm{~W}, 3.1 \% \mathrm{~V}$ and $8.5 \%$ Co. The experimental steels were selected due to their significantly divergent chemical composition. On the basis of that, the different levels of precipitation phenomena of different carbides types are expected. For Vanadis $6 \mathrm{P} / \mathrm{M}$ tool steel for cold work, the occurrence of Cr-based $\mathrm{M}_{7} \mathrm{C}_{3}$ type and V-based $\mathrm{MC}$ type carbides in the structure has been confirmed in the previous works [6,7]. In case of P/M HSS Vanadis 30, V-based MC type and $\mathrm{W}$-based M6C type carbides are expected to be present in the structure $[8,9]$. Commonly used parameters of CHT were employed for both materials (nitrogen gas quenching at pressure of 5 bars). In both cases, DCT step was inserted between quenching and tempering. Heat treatment parameters of the experimental materials are given in Table 1.

5 samples of Vanadis $6(10 \mathrm{~mm} \times 10 \mathrm{~mm} \times 100 \mathrm{~mm})$ and 5 samples of Vanadis $30(\emptyset 11 \mathrm{~mm} \times 100 \mathrm{~mm})$ were prepared for each combination of heat treatment parameters presented in Table 1. Surface roughness Ra of all samples for three point bending test was $0.2-0.3 \mu \mathrm{m}$. Test was carried out using Instron 5582 universal tensile testing machine with following parameters: the distance between supports was $80 \mathrm{~mm}$,

*Corresponding author: Sobotova J, Faculty of Mechanical Engineering, Czech Technical University in Prague, Karlovo nám 13, 12135 Prague 2, Czech Republic, Tel: 420224351111; E-mail: Jana.Sobotova@fs.cvut.cz

Received November 07, 2016; Accepted December 05, 2016; Published December 10, 2016

Citation: Sobotova J, Kuřík M, Krum S, Lacza J (2016) Effect of Sub-Zero Treatment on the Wear Resistance of P/M Tool Steels. J Appl Mech Eng 5: 243. doi: 10.4172/2168-9873.1000243

Copyright: (c) 2016 Sobotova J, et al. This is an open-access article distributed under the terms of the Creative Commons Attribution License, which permits unrestricted use, distribution, and reproduction in any medium, provided the original author and source are credited. 
Citation: Sobotova J, Kuřík M, Krum S, Lacza J (2016) Effect of Sub-Zero Treatment on the Wear Resistance of P/M Tool Steels. J Appl Mech Eng 5: 243. doi: 10.4172/2168-9873.1000243

Page 2 of 5

\begin{tabular}{|c|c|c|c|}
\hline Material & Austenitizing & DCT & Tempering \\
\hline Vanadis 6 & $1050^{\circ} \mathrm{C} / 30 \mathrm{~min}$ & - & $2 \times 530^{\circ} \mathrm{C}$ \\
\hline Vanadis 6 & $1050^{\circ} \mathrm{C} / 30 \mathrm{~min}$ & $-196^{\circ} \mathrm{C} / 4 \mathrm{~h}$ & $2 \times 530^{\circ} \mathrm{C}$ \\
\hline Vanadis 30 & $1100^{\circ} \mathrm{C} / 5 \mathrm{~min}$ & - & $3 \times 560^{\circ} \mathrm{C}$ \\
\hline Vanadis 30 & $1100^{\circ} \mathrm{C} / 5 \mathrm{~min}$ & $-196^{\circ} \mathrm{C} / 4 \mathrm{~h}$ & $3 \times 560^{\circ} \mathrm{C}$ \\
\hline
\end{tabular}

Table 1: Parameters of heat treatment.

loading rate of $1 \mathrm{~mm} / \mathrm{min}$ and loading force was applied to the central region up to the moment of the fracture. The fragments of the samples after the three point bending test were subsequently used for hardness measurements, metallography analysis and wear resistance test using pin on disc method. Metallographic samples were prepared using a standard procedure and observed with JEOL scanning electron microscope equipped with Oxford Instruments EDS analyzer. Six SEM micrographs at a magnification of $5000 \times$ were always evaluated in a sense of quantification of the structural changes. EDS mapping of Vanadis 30 was done using accelerating voltage of $15 \mathrm{kV}$ and a standard working distance of $8 \mathrm{~mm}$. Through the EDS maps the size distribution of carbides was determined using NIS ELEMENTS image analysis. Characterization of the carbide particles was carried out using point EDS analysis as well. The hardness was measured with Emco hardness tester using Rockwell C method (HRC). Five measurements were made on each specimen and the mean value and standard deviation was calculated. Wear resistance was determined using Tribometer THTS-CE-0000 by a pin on disc method according to the standard [10]. The surface of the testing material was polished to surface roughness lower than $0.04 \mu \mathrm{m}$. The test was running under dry sliding conditions at ambient temperature of $22^{\circ} \mathrm{C}$ and relative humidity of $40 \%$ to $50 \%$. All specimens were ultrasonically cleaned in ethanol and dried in air. $\mathrm{Al}_{2} \mathrm{O}_{3}$ ball with a diameter of $6 \mathrm{~mm}$ was used as a counterpart. Applied normal load was $5 \mathrm{~N}$, sliding speed $0,064 \mathrm{~m} / \mathrm{s}$, total sliding distance $100 \mathrm{~m}$ and track radius $2 \mathrm{~mm}$. Transversal sections of the groove after the pin on disc test were measured at 6 locations on each sample using Hommel T 1000 roughness tester. Illustration of the roughness tester record of transversal section measurement of the groove is in Figure 1.

From the thusly measured values volume loss was calculated. The volume loss served to determining wear rate.

\section{Results and Discussion}

The results of hardness measurement are in Figure 2. The picture shows the hardness values after CHT are similar for both steels. After DCT on the other hand, the hardness of Vanadis 30 practically does not change whereas that of Vanadis 6 is significantly lowered.

Presented fact is due to change of the tempering curve when DCT step is inserted between quenching and tempering of Vanadis 6. This phenomena regarding Vanadis 6 is described in [11].

Influence of DCT on bending strength of the both evaluated materials is in Figure 3.

These results are in good agreement with measured hardness values (Figure 2). It can be stated that the significant drop in hardness of Vanadis 6 steel after DCT causes a slight increase in its three point bending strength. Three point bending strength of Vanadis 30 steel after DCT remains almost unchanged within the standard deviation.

The results of the pin on disc test are in Figure 4. There is also a good correlation with the results already discussed. In case of Vanadis 6 steel after DCT there is a slight increase in wear rate, whereas Vanadis 30 does not show any effect of the cryogenic treatment on the wear rate.

Unexpected difference in values was observed in standard deviation values of the wear rate. Significantly higher standard deviation of the Vanadis 6 steel wear rate should be the subject of verification within further measurements.

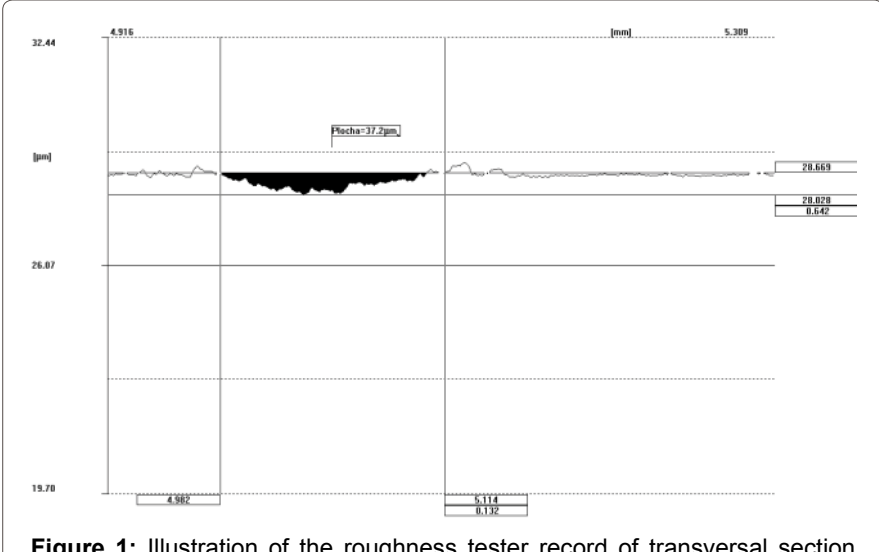

Figure 1: Illustration of the roughness tester record of transversal section measurement of the groove after the pin on disc test.

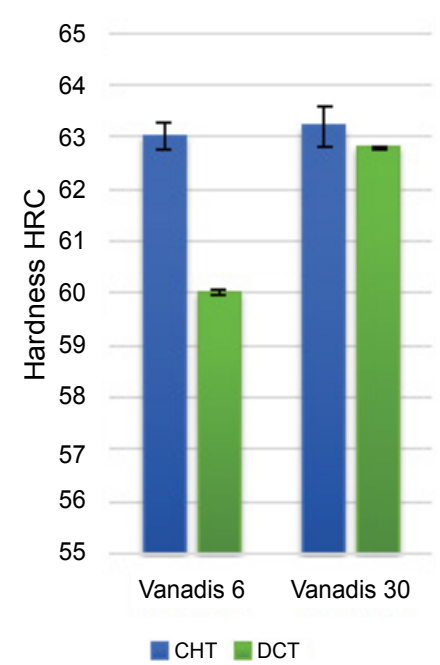

Figure 2: Influence of DCT on hardness of Vanadis 6 and Vanadis 30 steels.

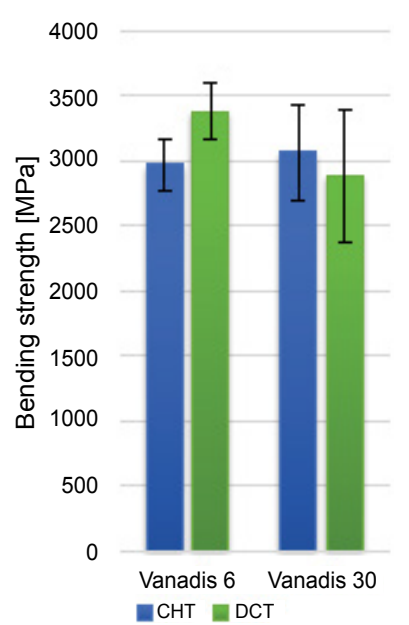

Figure 3: Influence of DCT on three point bending strength of Vanadis 6 and Vanadis 30 steels. 


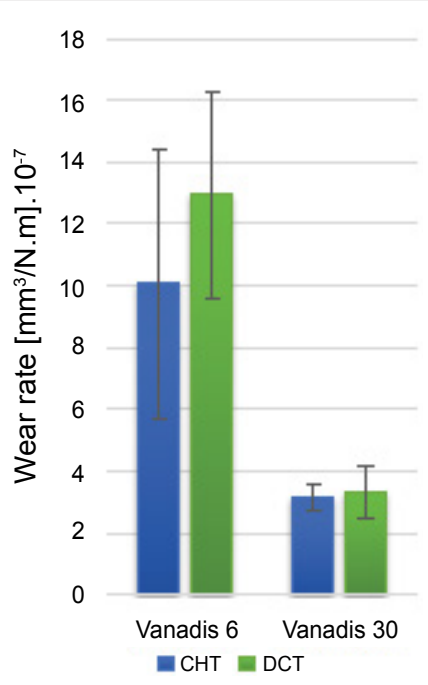

Figure 4: Influence of the DCT on wear rate of Vanadis 6 and Vanadis 30 steels.
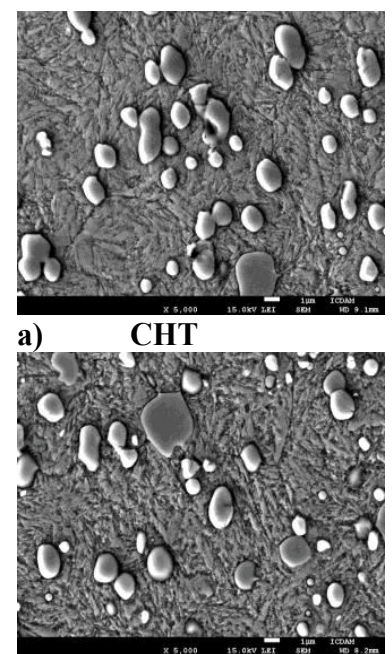

b)

DCT

Figure 5: Influence of DCT on microstructure of Vanadis 6 steel, austenitizing temperature of $1050^{\circ} \mathrm{C}(\mathrm{SEM})$.

Microstructure comparison of Vanadis 6 after CHT and DCT is in Figure 5. In both cases, the microstructure consists of tempered martensite matrix containing uniformly distributed carbides. Carbides are of two types. Eutectic ones contain predominantly vanadium and secondary ones contain mainly chromium. In comparison with Figure 5a, the microstructure in Figure 5b additionally shows, the presence of small globular carbides already identified in previous work for Vanadis 6 after DCT, but only in case of lower austenitizing temperature of $1025^{\circ} \mathrm{C}[7,12]$.

Even though the detailed quantitative analysis of carbide particles after DCT was not carried out within this work, it is possible to state that the presence of the fine globular carbides in the microstructure was confirmed. These carbides should ultimately cause greater wear resistance compared to the CHT which was confirmed in but not in this paper. It is necessary to note that in [7] the used pin on disc ball was made from bearing steel $100 \mathrm{Cr} 6$ and the utilized method of evaluation was different from the one used in this paper. In addition, based on previously obtained results of the authors and study of the available literature it is possible to assume that using of a higher loading forces during the pin on disc test would be more suitable [13].

Microstructure comparison of Vanadis 30 after CHT and DCT is in Figure 6. In both cases, the microstructure consists of tempered martensite matrix containing uniformly distributed lighter and darker carbides.

Detailed analysis of the carbide particles was carried out using EDS mapping. Figure 7a shows the reference image of Vanadis 30 steel after DCT. EDS maps of vanadium, tungsten, molybdenum and iron content are in Figures 7b-7e.

From the reference image of Vanadis 30 and corresponding EDS

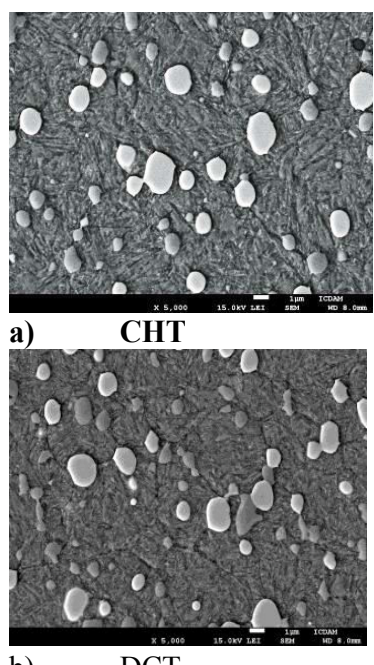

b)

DCT

Figure 6: Influence of DCT on microstructure of Vanadis 30 steel, austenitizing temperature of $1100^{\circ} \mathrm{C}(\mathrm{SEM})$.

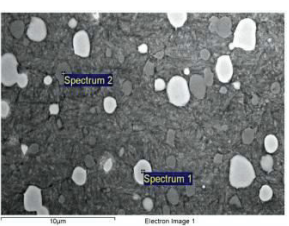

a)

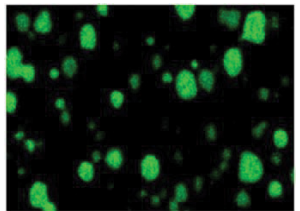

c) Mo

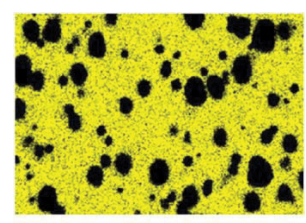

e) $\mathrm{Fe}$

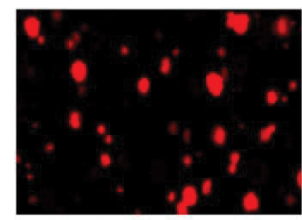

b) $\mathrm{V}$

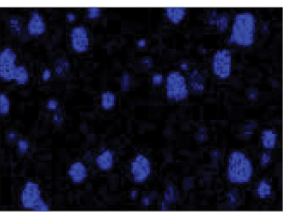

d) $\mathrm{W}$

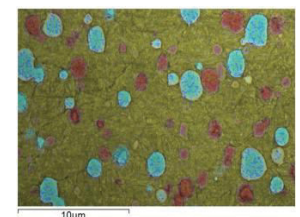

f) Mix
Figure 7: Metallographical analysis of Vanadis 30 after DCT (SEM, EDS). 
Citation: Sobotova J, Kuřík M, Krum S, Lacza J (2016) Effect of Sub-Zero Treatment on the Wear Resistance of P/M Tool Steels. J Appl Mech Eng 5: 243. doi: 10.4172/2168-9873.1000243

Page 4 of 5

maps of individual elements it is evident that the darker carbides contain predominantly vanadium and the lighter ones are tungsten and molybdenum based. Figure $7 \mathrm{f}$ shows an image composed of individual element maps. Matrix color proves the occurrence of all elements in the matrix whereas the colour of the larger carbides points at increased content of tungsten and molybdenum. The smaller carbides are predominantly vanadium based. These results were also confirmed by the point EDS analysis of the carbides marked in Figure 7a. EDS spectra of point analysis are in Figure 8. Spectrum 1 confirmed the carbides based on tungsten and molybdenum (hereinafter designated as $\mathrm{W}$-carbides). The spectrum contains a relatively high iron peak. Spectrum 2 characterizes vanadium based carbides (designated as $\mathrm{V}$-carbides). Molybdenum and tungsten are observed in this case as well, although their lower content is detected. The results of analysis of carbide particles is in good agreement with the results of the work [8], where authors characterized carbides in P/M HSS steel of chemical composition app. similar to Vanadis 30 .

EDS maps in Figures 7b-7d were further used for an evaluation of size distribution of the carbides after CHT and DCT in Vanadis 30 using image analysis. As mentioned before, DCT should cause an increase in number of the small carbides in the microstructure compared with the microstructure after CHT. Therefore, only the numbers of carbides in the size class up to $1 \mu \mathrm{m}^{2}$ are presented in Table 2 .

From the Table 2 it is evident that after DCT of Vanadis 30, number of carbides based on vanadium slightly decreases while the amount of carbides based on tungsten doubles. However in general, it can be stated that influence of DCT on fine carbides precipitation was not confirmed. Truth is that the result is in good accord with the results of mechanical tests and wear test of pin on disc, which has not shown any different values when compared with the state after CHT either.

However, it is imperative to say that the decisive factor regarding the usage of cryogenic treatment will be the results of the durability tests of real tools.

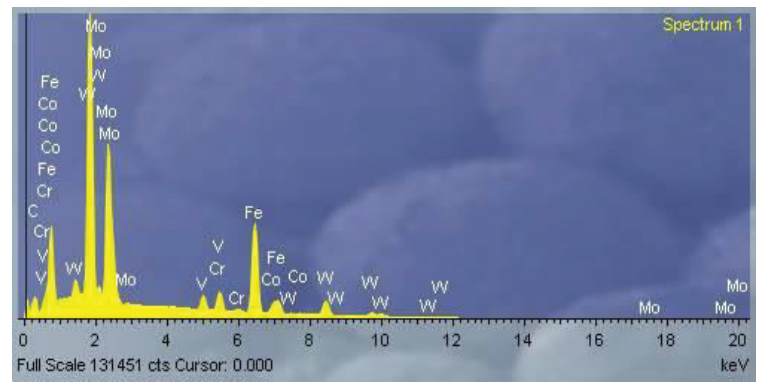

a) Spectrum 1

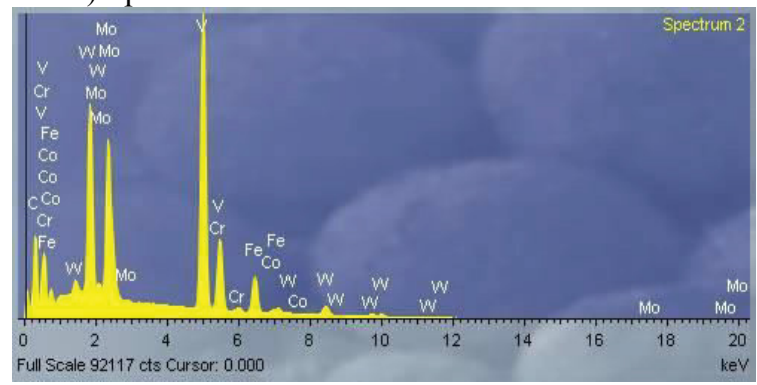

b) Spectrum 2

Figure 8: EDS spectra from the locations marked in Figure 7a EDS maps in Figure $7 \mathrm{~b}$.

\begin{tabular}{|c|c|c|c|}
\hline \multicolumn{4}{|c|}{ Number of carbide particles of the size up to $\mathbf{1} \mathbf{\mu m}^{\mathbf{2}}$} \\
\hline Vanadis $\mathbf{3 0}$ & V-Carbide & W-Carbide & Total \\
\hline CHT & 166 & 27 & 193 \\
\hline DCT & 158 & 57 & 215 \\
\hline
\end{tabular}

Table 2: Influence of DCT on number of carbide particles of the size up to $1 \mu \mathrm{m}^{2}$ in Vanadis $30 \mathrm{P} / \mathrm{M}$ HSS steel.

\section{Conclusions}

If DCT step is inserted between quenching and tempering of both Vanadis $6 \mathrm{P} / \mathrm{M}$ tool steel for cold work and Vanadis $30 \mathrm{P} / \mathrm{M}$ HSS steel, it is possible to state the following:

1. Significant drop in hardness due to DCT of Vanadis 6 causes a slight increase of three point bending strength. Three point bending strength of Vanadis 30 steel after DCT remains almost unchanged within the standard deviation.

2. In case of Vanadis 6 steel after DCT there is a slight increase in the wear rate, whereas Vanadis 30 does not show any effect of the cryogenic treatment on wear rate.

3. Metallographic analysis of Vanadis 6 after DCT confirmed higher amount of small globular carbides in comparison with state after DCT while the austenitizing temperature is $1050^{\circ} \mathrm{C}$.

4. Analysis of carbide particles in Vanadis 30 confirmed the presence of carbides based on vanadium and carbides based on tungsten and molybdenum.

5. After DCT of Vanadis 30, number of carbides based on vanadium slightly decreases while the amount of carbides based on tungsten increased.

6. DCT does not seem to cause any significant effect on fine carbides precipitation in Vanadis 30.

\section{Acknowledgement}

This work was supported by the Ministry of Education, Youth and Sport of the Czech Republic, program NPU1, project No. LO1207 and by the Grant Agency of the Czech Technical University in Prague, grant No. SGS15/149/OHK2/2T/12.

\section{References}

1. Akincioglu S, Gokkaya H, Uygur Al (2015) Review of cryogenic treatment on cutting tools. The International Journal of Advanced Manufacturing Technology 78: 1609-1627.

2. Gill S, Singh J, Singh R, Singh H (2011) Metallurgical principles of cryogenically treated tool steels-A review on the current state of science. The International Journal of Advanced Manufacturing Technology 54: 59-82.

3. Kalsi N, Sehgal R, Sharma V (2010) Cryogenic treatment of tool materials: A review. Materials and Manufacturing Processes 25: 1077-1100.

4. Das D, Dutta A, Ray K (2010) Sub-zero treatments of AISI D2 steel: Part I. Microstructure and hardness. Materials Science and Engineering: A 527: 2182-2193.

5. Jurci P, Sobotova J, Cejp J, Salabova P (2010) Effect of sub-zero treatment on mechanical properties of Vanadis 6 PM Ledeburitic tool steel. In: $19^{\text {th }}$ International Conference on Metallurgy and Materials, Conference Proceedings. Ostrava: Tanger Ltd., pp: 518-523.

6. Bilek P, Sobotova J, Jurci $P$ (2011) Evaluation of the microstructural changes in $\mathrm{Cr}-\mathrm{V}$ ledeburitic steels depending on the austenitization temperature. Materials and technology 45: 489-493.

7. Sobotova J, Jurci P, Dlouhy I (2016) The effect of sub-zero treatment on microstructure, fracture toughness and wear resistance of Vanadis 6 tool steel. Materials Science and Engineering: A 652: 192-204.

8. Godec M, Batic B, Mandrino D, Nagode A (2010) Characterization of the carbides and the martensite phase in powder-metallurgy high-speed steel. Materials Characterization. 61: 452-458. 
Citation: Sobotova J, Kuřík M, Krum S, Lacza J (2016) Effect of Sub-Zero Treatment on the Wear Resistance of P/M Tool Steels. J Appl Mech Eng 5: 243. doi: 10.4172/2168-9873.1000243

Page 5 of 5

9. Sobotova J, Kueik M, Cejp J (2015) Influence of heat treatment conditions on properties of high-speed P/M Steel Vanadis 30. Key Engineering Materials 647: $17-22$

10. American Society for Testing and Materials (2010) Standard test method for wear testing with a pin-on-disk apparatus: G99-05. Reapproved. Philadelphia USA: ASTM International.

11. Jurci $P$, Kusy M, Ptacinova J, Kuracina $V$ (2014) Long-term sub-zero treatment OD P/M Vanadis 6 Ledeburitic tool Steel-A preliminary study. In: International
Conference on Heat treatment. Praha: Asociace pro tepelné zpracování kovůECOSOND, S.R.O., 2014.

12. Jurci $P$, Dománkova $M$, Sobotova J (2015) Microstructure and hardness of subzero treated and no tempered P/M Vanadis 6 ledeburitic tool steel. Vacuum. 111: 92-101.

13. Das D, Dutta A, Ray K (2010) Sub-zero treatments of AISI D2 steel: Part II. Wear behavior. Materials Science and Engineering: A. 527: 2194-2206. 